\title{
Historia, política e ideología fundidas en la vida de Vicente Lombardo Toledano
}

\author{
DANIELA SPENSER
}

El artículo sigue la trayectoria de la liquidación de la Confederación de Trabajadores de América Latina, fundada en 1938 y disuelta en 1963. Es al mismo tiempo la trayectoria política e ideológica de un fragmento de la vida de Vicente Lombardo Toledano (1894-1968) que su protagonista no tenía interés en dar a conocer. Esta historia silenciada revela los entretelones de las actividades que Lombardo Toledano llevó a cabo en nombre del movimiento obrero del hemisferio occidental. El artículo explora los fenómenos que condujeron a ese desenlace y cuyo contexto era la Guerra Fría y la Revolución cubana.

PalABRAS ClaVE: Vicente Lombardo Toledano, biografía, Confederación de Trabajadores de América Latina, Unión Soviética, internacionalismo laboral

History, Politics and Ideology Fused in the Life of Vicente Lombardo Toledano

The article follows the trajectory of the Latin American Labor Confederation, founded in 1938 and dissolved in 1963. It is also the trajectory of a fragment of Vicente Lombardo Toledano's life (1894-1968), which he had no interest to divulge. This silenced history reveals Lombardo Toledano's behind the scenes activities, carried out on behalf of the labor movement in the Western hemisphere. The article explores the phenomena that brought about the dissolution of the confederation, examined against the background of the cold war and the Cuban revolution.

KEYWORDS: Vicente Lombardo Toledano, biography, Latin American Labor Confederation, Soviet Union, labor internationalism 
$\mathrm{n}$ los años sesenta del siglo Xx, el estadounidense James Wilkie y su esposa guatemalteca Edna Monzón llegaron a México para entrevistar a varios personajes que protagonizaron la Revolución mexicana y la vida política del país: Daniel Cosío Villegas, Jesús Silva Herzog, Emilio Portes Gil, Manuel Gómez Morín y otros. Vicente Lombardo Toledano, fundador de sindicatos, periódicos, revistas y partidos políticos, promotor de la educación obrera, tribuno polémico e interlocutor de presidentes, fue uno de los entrevistados. Desde que el fruto de esta investigación, México visto en el siglo XX, entrevistas de historia oral, fue publicado por primera vez en 1969, los historiadores han basado sus narrativas en lo que Lombardo Toledano les contó de su vida a los Wilkie, sin cuestionar la intencionalidad del entrevistado ni de los entrevistadores (Wilkie y Monzón de Wilkie, 1969; 2004).

La tesis del trabajo es que en las entrevistas que tuvieron lugar en 1964 y 1965 , Lombardo Toledano proyectó algunos pasajes de su vida no como ocurrieron, sino como hubiera querido que ocurrieran y como quería que la historia los recordara. También la historia era uno de sus instrumentos de combate para organizar y persuadir en aras de que otros adoptaran sus ideas y directivas. Ejemplifico esta tesis con la disolución de la Confederación de Trabajadores de América Latina (CTAL). El hecho de que el Departamento de Estado y la Federación Americana del Trabajo buscaran su destrucción no es una novedad, pero el que la Unión Soviética contribuyera a su desenlace merece una reflexión.

1 FHLT, leg. 1024, discurso de Vicente Lombardo Toledano en el restaurante Chapultepec, ciudad de México, 27 de julio de 1956. 


\section{Una vida eminente}

Vicente Lombardo Toledano fue una figura pública en Puebla, su estado natal, luego en el país y después fuera de él desde los años veinte y hasta los sesenta del siglo xx. Representaba la versión de la izquierda en México, en Latinoamérica y en el mundo que se había plegado al socialismo realmente existente en la Unión Soviética y los países bajo su hegemonía. Lo que Lombardo hacía, decía y escribía tenía una resonancia amplia, se tomaba en serio repetirlo, debatirlo o vilipendiarlo. Gran orador de extensa cultura, sin ambiciones de enriquecimiento, se le combatía por sus ideas porque no todos sus actos eran evidentes.

A Lombardo Toledano se le recuerda como uno de los jóvenes estudiantes de leyes y filosofía que en los años veinte creían en la redención de un México convulsionado por la Revolución. Lombardo tomó el camino del asesoramiento de trabajadores para que se organizaran en sindicatos y comprendieran las leyes laborales que emanaron de la Constitución de 1917, con las cuales pudieran defenderse contra los abusos de los empleadores, los funcionarios de los gobiernos estatales y el Estado mismo (Calderón, 1961; Krauze, 1976).

Sobresalía en su medio por la comprensión de las realidades de su tiempo y porque tenía la disposición, la voluntad y la energía para convertir las tribulaciones de los de abajo en representaciones organizadas, y cuando éstas resultaban insuficientes, en peticiones hacia los de arriba. En el camino se hizo del saber que convirtió en poder, que le permitió forjar nuevos cuerpos políticos y asumir funciones en las instituciones educativas, en la Confederación Regional Obrera Mexicana (CROM), en la Cámara de Diputados. Fuera de México, mostró sus habilidades en la Organización Internacional del Trabajo, en las organizaciones sindicales de Latinoamérica y en la fundación de instituciones y centrales obreras nacionales como la Confederación

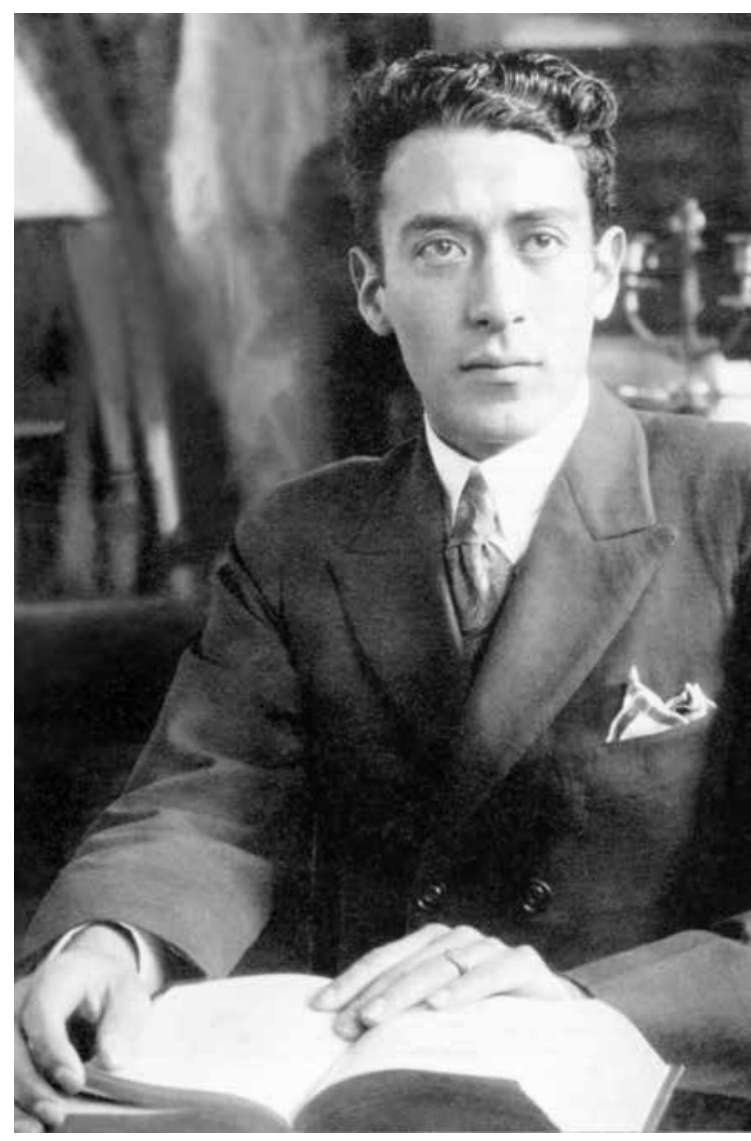

Centro de Estudios Filosóficos, Politicos y Sociales Vicente Lombardo ToledAno $\vee$ Vicente Lombardo Toledano.

de Trabajadores de México (CTM), en 1936, y la Confederación de Trabajadores de América Latina, su hazaña continental en los años treinta.

Las circunstancias lo propiciaron. Lombardo supo aprovechar el gobierno del presidente Lázaro Cárdenas en México y del presidente Franklin Delano Roosevelt en Estados Unidos para poner el movimiento obrero al servicio del Estado progresista tanto en México como fuera, con la esperanza de fortalecer aquella alianza que, dirigida por una elite que Lombardo encabezaba, se enfilara hacia la emancipación de los trabajadores. Paso a paso, adoptó el marxismo-leninismo en su versión stalinista de la Unión Soviética como el credo de su vida 
y lo practicó con singular tenacidad. Con certeza doctrinal fundó el Partido Popular Socialista, el periódico El Popular, sindicatos, como el de maestros, y dirigió la Universidad Obrera desde que la creó en 1936 hasta que la muerte lo sorprendió en 1968.

El anticomunismo y la Guerra Fría interior y exterior de los años cincuenta y sesenta no disminuyeron su ímpetu. El intervencionismo estadounidense, desde los derrocamientos de Jacobo Árbenz, en Guatemala, en 1954; de João Goulart, en Brasil, y de Juan Bosch, en la República Dominicana, en los años sesenta, vigorizó su antiimperialismo. Su adhesión a la Revolución cubana parecía demostrar que estaba sobre la cresta de la historia que ocultaba sin embargo el gradual anquilosamiento de su ideología. Su defensa de las intervenciones militares de la Unión de Repúblicas Socialistas Soviéticas (URSS), en Hungría, en 1956, y en Checoslovaquia, en 1968, para salvaguardar la hegemonía y la dominación de la potencia en su esfera de influencia, iban a contracorriente de las demandas de las poblaciones en Europa del Este de humanizar el socialismo realmente existente.

A pesar del estancamiento ideológico y de haber perdido a manos del anticomunismo y la Guerra Fría, entre otras armas, las organizaciones que había fundado y dirigido - la CTM, en 1947, y la CTAL, formalmente en 1963, pero que se le escapaba de las manos desde antes-, Lombardo Toledano sobresalía hasta en su declive. Nunca dejó de ser un tribuno y comentarista influyente de los acontecimientos nacionales e internacionales en periódicos y revistas, como Siempre!, y en las universidades del país entero.

Lombardo Toledano era renuente a escribir sus memorias o autobiografía, pero dio un sinfín de entrevistas y divulgó numerosos discursos que fueron autobiográficos a su manera. Decía una y otra vez que subordinaba la subjetividad a las leyes naturales e históricas y que sus pérdidas personales palidecían en comparación con lo que creía que era el progreso ascendente de la humanidad. Las entrevistas con James y Edna Wilkie reflejan esa contradicción entre el eminente individuo, la retórica de su fusión con las masas trabajadoras y su convicción en el papel dirigente de personas como él, que obedecían las inexorables leyes históricas. Las respuestas a las preguntas de Wilkie no siempre reflejaban la vida de Lombardo y los acontecimientos en los que participó tal como ocurrieron, sino como Lombardo quería proyectarlos. La historia le servía como un articulador de sus propuestas políticas, pero la tensión entre lo individual y lo universal de su pretensión y discurso lo obligaba a hacer ajustes a la historia que ejemplificaré a continuación.

\section{Los entrevistadores y las entrevistas}

James y Edna Wilkie se prepararon a profundidad para las entrevistas. Leyeron todo sobre y de sus personajes. Recién casados y con el aval de la Universidad de Berkeley, llegaron a México en 1963. Fue una época de optimismo, del desarrollo estabilizador, del crecimiento económico, de la inauguración de escuelas y la construcción de puentes (Rodríguez, 1995: i, xxii-xxvii; iv, xxv-xxvi). Según admiten, los Wilkie no llegaron a México en busca de la verdad sino de puntos de vista, en el entendido académico e ingenuo de que un "individuo explica sus actos racionalmente, ya que actúa de acuerdo con la información que posee" y que "lo que los hombres creen sinceramente que pasó viene a ser tan importante como lo que sucedió en la realidad" (Wilkie y Monzón de Wilkie, 1969: 2). ${ }^{2}$ Los Wilkie creían que producían un testimonio cercano a la verdad,

Quise consultar a James Wilkie, hoy profesor en la Universidad de California en Los Ángeles, sobre las entrevistas que había conducido en los años sesenta, vistas en retrospectiva. Por desgracia, Wilkie no contestó mis correos electrónicos, no obstante haberlos recibido.
} 
útil para las generaciones venideras sobre el desarrollo nacional de México y una nueva perspectiva sobre el pasado de México. James Wilkie aceptó también que cada personaje decía lo que decía para proteger su autoimagen. Éste fue el caso de Lázaro Cárdenas, quien se negó a concederle una entrevista porque, cauteloso ante las distorsiones que las entrevistas provocarían, prefirió perpetuar el mito sobre su persona y su administración (Rodríguez, 1995: i, xxviii; iv, xxxviii).

El primer contacto con los mexicanos lo hacía Edna. Daba buenos resultados. En general, los entrevistados estaban de acuerdo en dar las entrevistas porque no temían que la inocente pareja representara a alguien en México. Algunos sospechaban lo que otros desechaban: que eran agentes de la Agencia Central de Inteligencia - CIA, por sus siglas en inglés-, como solía verse a los estadounidenses que en esos años venían a estudiar cosas mexicanas. Después de los preliminares, James y Edna arrancaban hacia sus entrevistas en su Ford amarillo de 1954.

En mayo y junio de 1964, los Wilkie hicieron las dos primeras entrevistas con Lombardo. Era tan desconfiado que dispuso de una segunda grabadora para obtener los mismos registros que los entrevistadores, "como medida precautoria". Para el beneplácito de los Wilkie, "Lombardo tomó muy en serio nuestro proyecto. Llegaba a la cita con nosotros preparado, con sus propias notas para ayudarnos" (Wilkie y Monzón de Wilkie, 2005, IV: 120-121), y leía la versión final de las entrevistas antes de que fueran publicadas. En las conversaciones estaba rodeado de un séquito, una secretaria tomaba notas en taquigrafía y dos ayudantes grababan las entrevistas, de manera que Lombardo hablaba a dos micrófonos a la vez. Puntual y disciplinado, fumador, inquieto, exigente con sus ayudantes, su agenda era su reloj al minuto. Lombardo fue uno de los suspicaces sobre los agentes de la CIA:

Pero viéndonos tan jóvenes, en ese carro tan flamante, que los agentes de la CIA no usaban, y además, comenzando las entrevistas con preguntas sobre temas como el de la familia, el lugar de nacimiento y el origen e historia de los padres o sobre cómo era la vida entonces, sin tocar temas del momento, era obvio que no éramos de la CIA (Rodríguez, 1995: iv, xxvii-xliii; Wilkie y Monzón de Wilkie, 2004, IV: 120-121).

Con el tiempo, Lombardo se relajó. Debió darse cuenta de que los Wilkie eran un par de bienintencionados inocentes a los que podía dar lecciones sobre su vida y la vida de México, empezando, insospechadamente, por la familia. Sus respuestas a las preguntas de los Wilkie siguieron otra lógica que la de los entrevistadores. Manipuló la información que dio de sí mismo y de su vida pública, ocultó lo que no quería que se supiera y contribuyó a alterar el pasado de cuya construcción fue uno de los maestros. Lombardo aprovechó las entrevistas para presentarse en términos absolutos y dar testimonio de su vida como el ejemplo de un carácter templado, convicciones firmes y compromiso a favor de los demás.

\section{El telón de fondo}

Para los años sesenta, Lombardo Toledano había acumulado méritos y pérdidas. La más significativa fue la disolución de la CTAL, que había fundado con otros dirigentes sindicales en 1938. Lombardo Toledano fue compelido a hacerlo, según él, porque la CTAL había concluido su misión histórica. Esta célebre frase lapidaria, que no ha sido examinada por los historiadores, oculta más de lo que revela (Lombardo, 1964). La fundación de la CTAL fue una hazaña continental, mientras su disolución, en 1963, fue una debacle que era contraproducente analizar en público. La Guerra Fría y el gobierno de Estados Unidos provocaron la crisis en la CTAL, y los gobiernos de Latinoamérica "se prestaron para destruir el movimiento obrero independiente", dijo 
Lombardo al entrevistador. Surgieron nuevas agrupaciones que no estaban afiliadas a la CTAL y la propuesta de una nueva central latinoamericana. Con candidez, Lombardo admitió que la CTAL había sido señalada como comunista e instrumento de Moscú "por la propaganda que se hizo contra ella durante la Guerra Fría". Para no obstaculizar aquel proceso en gestación, Lombardo la disolvió. "Y es todo", remarcó de manera categórica (Wilkie y Monzón de Wilkie, 1969: 360-361; Herrera, 2013b: 195$218 ; 2014){ }^{3}$

Lombardo Toledano siempre negaba haber recibido apoyo económico para mantener la CTAL con vida. A la pregunta de Wilkie de si recibía dinero de la URSS, contestó: "Ojalá hubiéramos recibido dinero de Rusia, hubiera sido muy útil. Nunca lo hemos recibido de nadie". Añadió: "No tengo inconveniente en recibirlo, del infierno o del cielo, con tal que me sea útil para combatir por las ideas que yo persigo" (Wilkie y Monzón de Wilkie, 1969: 363). La respuesta queda desmentida por los archivos de la extinta Unión Soviética y el archivo de Lombardo Toledano, como se verá más adelante.

La CTAL había sido mantenida por las arcas de los países del bloque socialista desde los años cincuenta. Las donaciones habían disminuido en los años sesenta a la vista de la menguada importancia que llegó a tener en Latinoamérica durante la era de la Revolución cubana. Pero había más. Así como en el caso de los asuntos económicos de la CTAL, Lombardo no creía necesario dar explicaciones a nadie sobre su proceder, pues el fin justificaba los medios. El fin, en Latinoamérica, era el triunfo del nacionalismo sobre el imperialismo estadounidense, y en última instancia, la instauración del socialismo sobre la tierra, para lo cual era indispensable seguir fortaleciendo a la Unión Soviética.

La Guerra Fría era el telón de fondo del desarrollo y de la disolución de la CTAL, lo que implicaba admitir que en la correlación de fuerzas Estados Unidos era superior a la URSS en el hemisferio occidental. A pesar de su derrota en Playa Girón en abril de 1961, Estados Unidos salió ileso de la crisis de los misiles en octubre de 1962, mientras que la URSS tuvo que replegarse de Cuba con todo y sus ojivas nucleares. Sin embargo, Lombardo era optimista: "sufriremos derrotas y tendremos victorias parciales; pero el futuro pertenece por entero a la clase obrera" (Lombardo, 1964: 44). Para no desanimar a sus seguidores, Lombardo ocultó la otra parte de la historia, sin la cual no se comprende la trayectoria y la disolución de la CTAL. Tampoco se la contó a James Wilkie.

\section{La historia silenciada}

La CTAL, Lombardo y sus camaradas aspiraban a crear una organización político-sindical en la que la fuerza sindical fortaleciera su lado político. El objetivo era luchar contra el imperialismo, debilitar la fuerza económica y política de Estados Unidos en el continente y promover la democracia popular, entendida como la alianza de los sindicatos con el Estado, con los industriales o con quien conviniera para conquistar posiciones tanto nacionales como internacionales. El debilitamiento de Estados Unidos era ganancia para la Unión Soviética. Uno de los medios de la CTAL para llegar al fin deseado era la Federación Sindical Mundial (FSM), de la que Lombardo Toledano era uno de los vicepresidentes. ${ }^{4}$

La CTAL fue uno de los principales brazos y el enlace con Latinoamérica de la FSM desde su fundación, en París, en 1945. La Federación surgió a imagen y semejanza de la alianza entre las potencias en la Segunda Guerra Mundial, y como alianza

\footnotetext{
3 A pesar de las fechas que Herrera (2013b) se propone "(re) significar", no toca la disolución de la CTAL.

4 En el más reciente trabajo sobre la CTAL, la investigación comprueba que la acción política era una palanca para la política sindical (Herrera, 2013b).
} 
no sobrevivió mucho tiempo. En 1949 se dividió en dos bloques de la misma forma que el mundo. De allí en adelante, Lombardo Toledano y la CTAL pertenecieron al bloque soviético, aunque en público Lombardo destacaba la defensa de los intereses de los trabajadores latinoamericanos, no los de una potencia, un sistema y una ideología, a pesar de que se fundían en su concepción del mundo (Sturmthal, 1948: 624-638; Schwartz, 1963; Carew, 1984: 218-244).

Los sindicatos y las centrales obreras de los países europeos y del Congreso de Organizaciones Industriales - CIO, por sus siglas en inglés - norteamericano abandonaron la Federación Mundial. Esto debilitó a la federación y también a la CTAL, que no pudo reponerse del golpe y hacerle frente, en un ambiente de agresividad de Estados Unidos en el hemisferio y de dictaduras militares. No obstante, la Federación se convirtió en el apoyo de la organización latinoamericana, fue solidaria y brindó ayuda económica a los obreros reprimidos, en huelga, desempleados o encarcelados, pues la vida sindical en varios países estaba en ruinas. En Colombia estalló la Violencia en 1948 y detuvo la vida institucional del país. En mayo de 1948, la dictadura militar reprimió la huelga general de petroleros en Venezuela, que demandaban el aumento de salarios y la defensa de la economía nacional contra las compañías angloamericanas. Los sindicatos petroleros fueron disueltos y 3000 obreros fueron arrestados, entre ellos estaba Jesús Faría, dirigente de la CTAL. En Cuba, el gobierno incautó el periódico Hoy para silenciar la defensa independiente de los trabajadores. ${ }^{5}$ El panorama latinoamericano era desolador.

Socialistas y sindicalistas de varios países dejaron de ver en la CTAL un medio obrero, la percibían como un instrumento de la política exterior de la URSS. Era cierto que había perdido eficacia ante obstáculos monumentales, como los gobiernos dictatoriales, la Federación Estadounidense del Trabajo y las compañías norteamericanas protegidas por el gobierno de Estados Unidos. Además, Lombardo Toledano dejó de ser el interlocutor de los gobiernos regionales, como había sido en los años treinta y durante la guerra. Debido a la eliminación del ala progresista del gobierno de Estados Unidos y de los comunistas del CIO, Lombardo perdió aliados en el gobierno vecino y en las organizaciones sindicales, salvo excepciones que no compensaban la fuerza de las otras. En esta nueva constelación, el gobierno de México, los del bloque soviético y las organizaciones internacionales adheridas a él eran sus instrumentos para maniobrar en el país, en Latinoamérica y en el adverso escenario internacional.

El establecimiento de la Confederación Interamericana de Trabajo, en 1948, y de la Organización Regional Interamericana de Trabajo, en 1951, por la Federación Americana para torpedear a la CTAL, junto con el retiro de centrales y sindicatos de la CTAL, fueron hechos interpretados por la dirección de la Federación Mundial, sin entender bien la trayectoria del hemisferio occidental, como la debilidad de la organización fundada por Lombardo y de Lombardo mismo.

Desde la perspectiva europea, las dictaduras de Manuel Odría en Perú (1950-1956) y de Anastasio Somoza en Nicaragua (desde 1937), de Carlos Castillo Armas en Guatemala (1954-1957), de Leónidas Trujillo en la República Dominicana (1930-1961), de Fulgencio Batista en Cuba (1955-1959), de Juan Vicente Gómez en Venezuela (1931-1935) o de Gustavo Rojas Pinilla en Colombia (1953-1957), la mayoría de duración más prolongada que los periodos de gobierno constitucionales, eran indescifrables. El secretario general de la Federación Mundial,

5

FHLT, leg. 792, Santos Yorme, "Venezuela en el año 1950" y Caracas, 11 de enero de 1950, Domingo Barria, "Panamá", 26 de enero de 1950; FHLT, leg. 800, Vicente Lombardo Toledano a Saillant, ciudad de México, 11 de mayo de 1950; FHLT, leg. 806, Lázaro Peña a Vicente Lombardo Toledano, La Habana, Cuba, telegrama, 24 de agosto de 1950. 


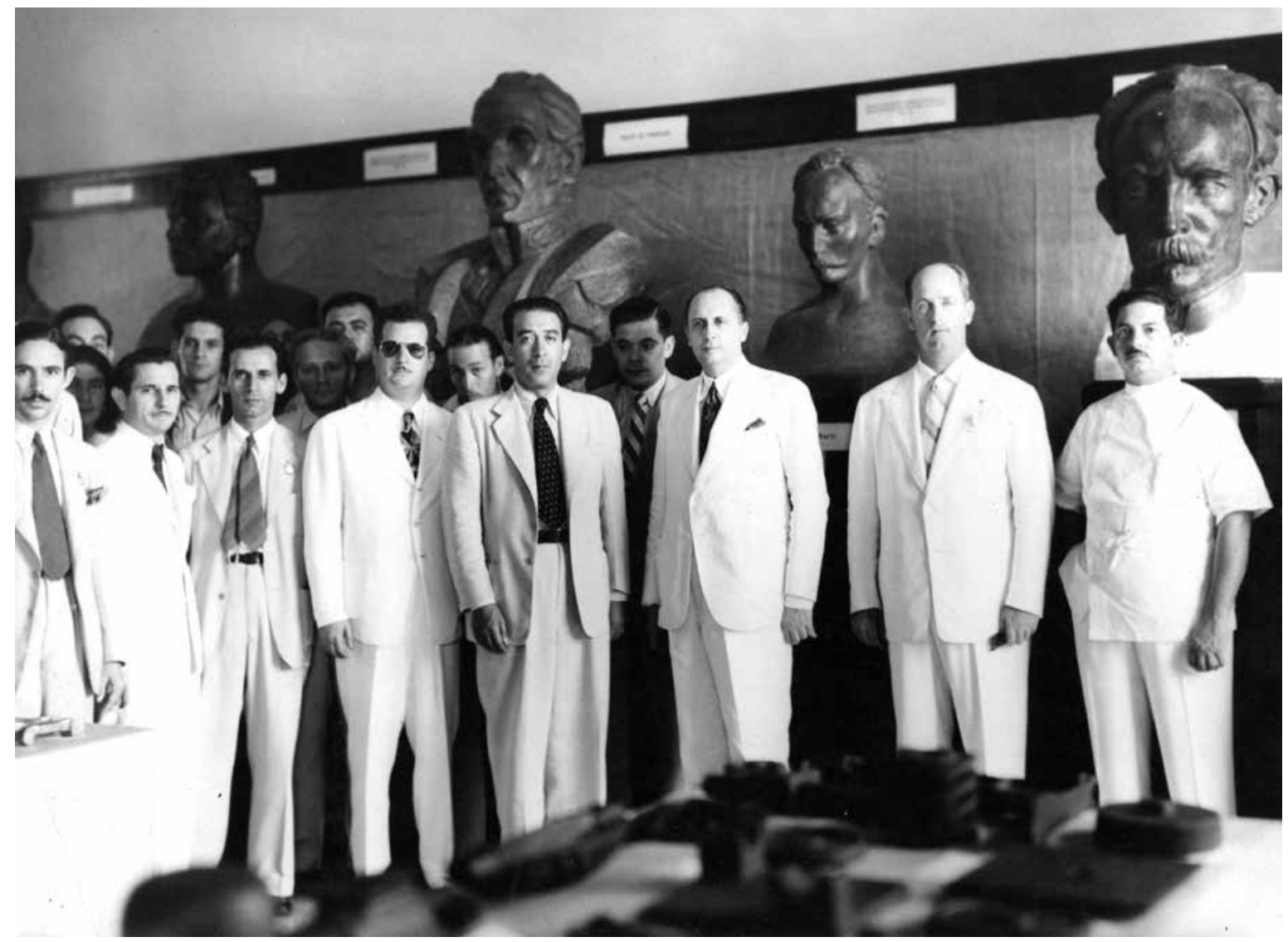

Centro de Estudios Filosóficos, Políticos y Sociales Vicente Lombardo Toledano reunión con líderes sindicales en Cuba.

el francés Louis Saillant, no profundizó en el análisis de los sucesos latinoamericanos cuando acusó a la CTAL de aplicar la línea y las orientaciones de la Federación de manera superficial. ${ }^{6}$ Tampoco pensó en la eventualidad de correos irregulares, interceptados o perdidos que impedían la comunicación entre un país y otro en un vasto continente.

Con anterioridad a la Revolución cubana, la penetración de la Unión Soviética en Latinoamérica no tenía posibilidades de éxito debido a la avasalladora hegemonía de Estados Unidos. Su influencia en los sindicatos por medio de la Federación Mundial y la CTAL era el medio más idóneo. Al no prosperar, la URSS utilizaba a la Federación Mundial para denostar a la CTAL como sectaria y oportunista, sin capacidad de aliviar la precariedad existencial de los trabajadores. Para Lombardo debió ser amargo escuchar a Saillant decir que la CTM, que Lombardo había fundado en 1936 y de la que fuera expulsado en 1948 por diferencias ideológicas con sus dirigentes, se había retirado de la Federación sin que la CTAL fuera capaz de atraer a "las masas" cetemistas a sus filas. ${ }^{7}$

\footnotetext{
$6 \quad$ FHLT, leg. 840, reunión conjunta de la Federación Sindical Mundial y el comité central de la CTAL, Viena, Austria, 28 de noviembre de 1951.

7
} 
Era cierto que la autoridad de Lombardo había disminuido en Latinoamérica pero ello se debía en parte a que la misma Federación había ayudado a erosionarla con la desconfianza en la capacidad de la CTAL de actuar como el vehículo para fortalecer el movimiento obrero en el continente y para defender la imagen y la política de la URSS en sus esferas de interés. Se rumoraba que la sede de la CTAL sería transferida de México a Santiago de Chile y que Lombardo sería reemplazado por el comunista chileno Bernardo Araya. ${ }^{8}$

En 1952, Lombardo Toledano estuvo ocupado con su campaña por la presidencia de México y no tuvo tiempo para la CTAL. Cuando retomó el trabajo a finales del año, después de haber perdido en la contienda electoral, como era de esperarse, el panorama latinoamericano tenía visos de cambio. En Bolivia, el gobierno nacionalizó las minas. Juan Lechín, a la cabeza del movimiento de los obreros de estaño en el sindicato minero, no aceptó afiliarse a la CTAL. La Federación Mundial observó la marginación de la CTAL y requirió de Lombardo que la convocara, con la organización controlada desde Estados Unidos y la peronista Confederación General de Trabajadores argentina, para discutir un programa común en un congreso en Santiago de Chile en marzo de 1953. Esta política de frentes amplios había sido ejercida por la Unión Soviética en los años veinte y treinta por medio de la Internacional Comunista, su brazo de extensión ideológica internacional, y había dado buenos resultados para la masificación de los partidos comunistas. Ahora, en los años cincuenta, la Federación Mundial exigía a la CTAL que sus asuntos fueran discutidos por los trabajadores de todas las tendencias. ${ }^{9}$

La convocatoria al congreso, que Lombardo emitió al volver de Viena, donde debió recibir instrucciones, perdió el tono combativo de las anteriores. En el machote que la CTAL envió a las organizaciones, apenas dos semanas antes de que el congreso tuviera lugar, se aseguraba que su presencia no representaba "ningún compromiso sino sólo un acercamiento y "un intercambio de opiniones". El congreso de Santiago, a finales de marzo, fue una reunión desangelada con pocos delegados. La muerte de Stalin, "uno de los más grandes genios de la humanidad", pudo haber contribuido al decaimiento de algunos ánimos. Lombardo, sin embargo, aprovechó la ocasión para desviar la acusación de la CTAL por la debilidad del movimiento obrero y dirigirla a sus adversarios que representaban el anticomunismo y el antisovietismo que denunció junto con los monopolios y el imperialismo norteamericanos (Lombardo, 2004: 137, 183-211; Herrera, 2013a: 308). A pesar de que seguía con fidelidad las instrucciones que provenían de Moscú, en su discurso dio a entender que no había manera de forjar unidad con organizaciones que habían nacido del antagonismo con la CTAL.

Sin embargo, ésa era la línea dentro de la nueva, aunque vieja, política de coexistencia pacífica entre los dos sistemas económicos e ideológicos que la Unión Soviética exigía que sus aliados adoptaran. El año de 1953 fue el de la insurgencia obrera en Alemania oriental y en Polonia contra la falta de bienes de consumo y la evidencia de disparidad entre el bienestar de un lado de la frontera y la escasez del otro. Uno de los propósitos de la coexistencia pacífica era disminuir la fabricación de armamentos que se producían en la URSS y sus países aliados a costa del gasto social. Había que cooperar con Occidente, no competir. Eso no quería decir que la teoría no siguiera enseñando que el capitalismo se

8

FHLT, leg. 869, Secretariado de la FSM a Vicente Lombardo Toledano, Viena, 29 de noviembre de 1952; National Archives and Record Administration, CIA Confidential Security Information, exp. 398.062-SA/1-2153, Carlos Hall al Departamento de Estado, Santiago, Chile, 21 de enero de 1953.

9 FHLT, leg. 869, "La situación del movimiento obrero en México y en América Latina y sus perspectivas", de Vicente Lombardo Toledano, noviembre de 1952. 
estaba desintegrando. Era una estrategia para empujar al sistema contrario hacia su desintegración por otros medios y fortalecer las economías de los países socialistas para rebasar a los capitalistas. ${ }^{10}$

La política de coexistencia pacífica de la URSS, y por lo tanto, de la Federación Mundial en Latinoamérica, sacudida por la violencia, tenía eco en la dirigencia de la CTAL y de los partidos comunistas. Lombardo Toledano exhortaba a la solidaridad con los dirigentes y sindicatos reprimidos, pero era más una declaración de fe que pauta para la acción:

Los monopolios no pueden hacer todo lo que quieren, el imperialismo-factor de reacción, de guerra y de miseria no puede hacer evolucionar la situación como él quisiera. Somos un elemento determinante de la situación mundial y de su evolución. Las fuerzas del trabajo, del progreso y de la paz son inmensas en el mundo y nuestra causa es justa. Ninguna fuerza podrá impedirnos ir hacia adelante. ${ }^{11}$

Mientras Lombardo enviaba invitaciones a congresos y reuniones, circulares y noticias sobre las protestas contra las represiones y abogaba ante el gobierno mexicano para que otorgara asilo a los desdichados guatemaltecos después del golpe contra Jacobo Árbenz en 1954, los guerrilleros cubanos, más de 30 años menores que él, después de haber dejado de creer en la fórmula de la coexistencia pacífica, empezaron a imaginarse en la clandestinidad una Cuba y una Latinoamérica sin tiranías.

El venezolano Rodolfo Quintero, en México, después de haber sido expulsado de su país, electo al comité central de la CTAL, hizo un diagnóstico del debilitamiento de la organización. El que la atomización sindical se hubiera debido al imperialismo, a la organización controlada por los norteamericanos y al gobierno represivo de Venezuela era de esperarse, pero ¿a la CTAL? Quintero puso el dedo en la llaga: se debía "al hecho de haber trasladado al terreno de la lucha sindical los choques y las divergencias partidistas. Deformando el carácter amplio y unitario de los sindicatos, transformándolos en reductos sectarios al servicio de grupos y facciones políticas" ${ }^{12}$ No había democracia sindical y los obreros sabían poco de lo que hacían o deshacían los dirigentes en su nombre.

Desde su perspectiva venezolana, Quintero señaló el vicio con el cual la CTAL había nacido y que reflejaba la visión de Lombardo Toledano: la organización era asunto de una elite pensante que transmitía a los obreros ideas prefabricadas que debían poner en marcha:

Estos por arriba, nombran delegados a los congresos internacionales, envían noticias a la prensa obrera del extranjero, ponen en boca de los obreros palabras que no han pronunciado, toman resoluciones en nombre de estos, etc. Tal irrespeto por la opinión de los trabajadores, tal costumbre de no consultarlos, conduce a la presentación de informes en las reuniones internacionales alejados de la realidad; conduce al suministro de noticias, que al conocerlos, los obreros venezolanos son los primeros en extrañarse, etc. ${ }^{13}$

A pesar de las críticas que la CTAL recibía, la Federación Mundial seguía inyectándole vida. En febrero

"WFTU, 1952-1953", caja 66, exp. 3, The George Meany Memorial Archives, International Affairs Department, Jay Lovestone Files, 1944-1973; FHLT, leg. 903, "Apuntes sobre la reunión del buró ejecutivo de la FSM”, de Vicente Lombardo Toledano, Praga, Checoslovaquia, 3 de agosto de 1953.

11 FHLT, leg. 945, Vicente Lombardo Toledano a Amado Zapata, ciudad de México, 10 de julio de 1954.

12 FHLT, leg. 960, "Contribución a la solución del problema de la división sindical en Venezuela", ciudad de México, noviembre de 1954; FHLT, leg. 970, Rodolfo Quintero al presidente y secretario de la CTAL, ciudad de México, 21 de febrero de 1955.

13 FHLT, leg. 970, "Contribución a la solución del problema de la división sindical en Venezuela", ciudad de México, noviembre de 1954. 


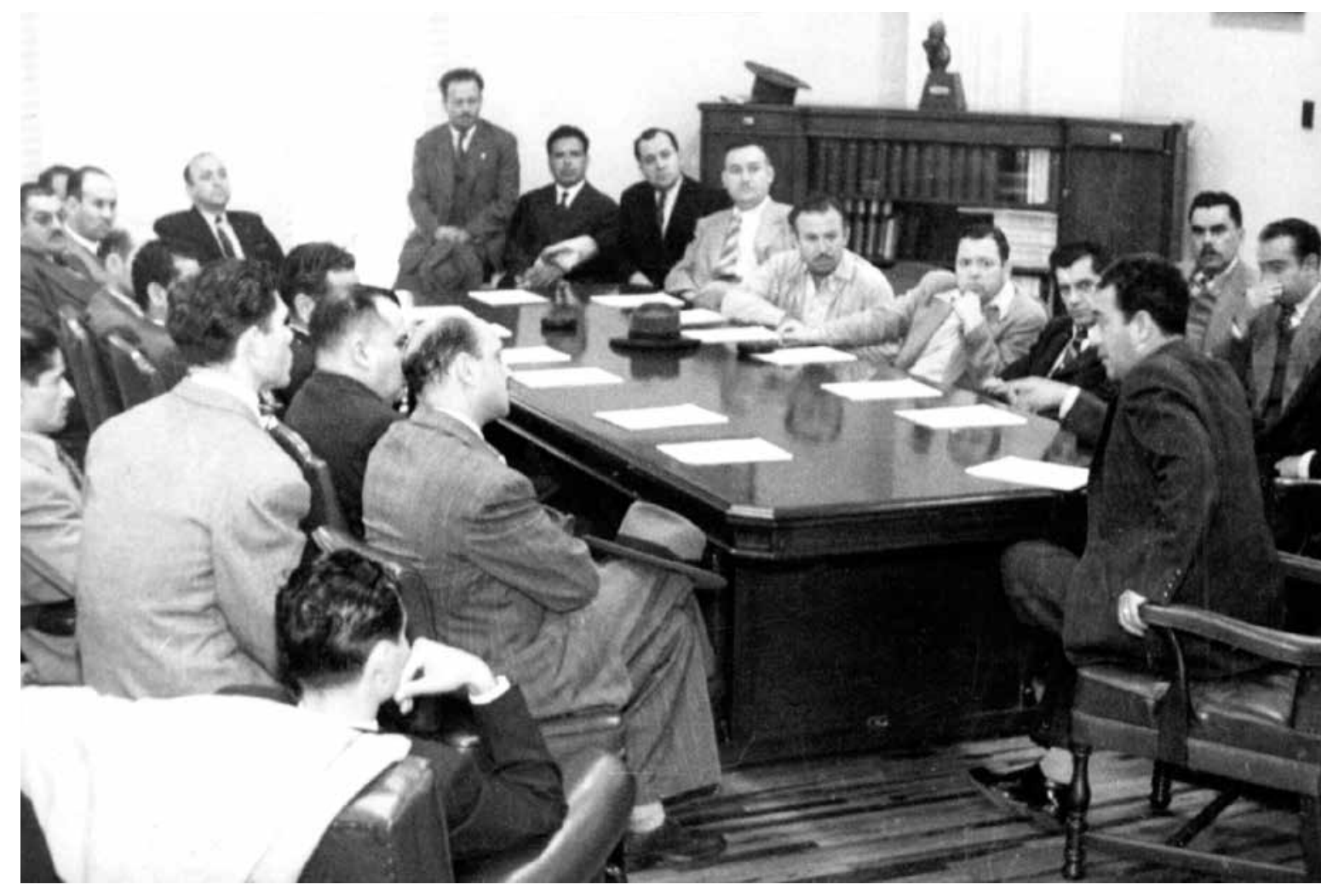

Centro de Estudios Filosóficos, Politicos y Sociales Vicente Lombardo Toledano vicente Lombardo Toledano durante una reunión con los dirigentes petroleros en las oficinas de la CTAL.

de 1955 le otorgó 3250 libras esterlinas "como la cuarta parte del presupuesto de la CTAL del año, y 1250 libras esterlinas, la cuarta parte también del presupuesto para la Revista”. ${ }^{14}$ Las valijas diplomáticas eran el mejor medio para que el dinero llegara a México desde Checoslovaquia, China o Rumania, los países tributarios de la Federación y en los que la membresía de los sindicatos era obligatoria. También contribuían a su bolsa sindicatos comunistas franceses e italianos. En Latinoamérica, el dinero se concentraba en México y Lombardo Toledano distribuía los fondos de acuerdo con las necesidades, sobre todo con el costo de los traslados de los delegados de un país a otro y a las reuniones de la CTAL y de la Federación en Europa. El dinero se utilizaba también para ayudar a obreros en huelga o a los que sufrieran algún desastre, como inundación o explosión, como sucedió con los mineros de Nueva Rosita, Coahuila, en huelga en 1951. Una parte del dinero sufragaba El Popular. Los fondos se depositaban en una cuenta del banco militar soviético, en el sector de Viena, bajo el control de la URSS —hasta 1956, cuando la Federación fue expulsada de Austria y acogida por Checoslovaquia-, luego se transfería vía el National City Bank de Nueva York. Para evitar la intercepción de sus impresos por la CIA, el secretariado de la Federación los transportaba por la compañía Air France, en cuyo Louis Saillant, ciudad de México, 24 de febrero de 1955. 
sindicato laboraban pilotos y trabajadores afines al Partido Comunista. ${ }^{15}$

Una delegación checoslovaca de funcionarios del Consejo Central de Sindicatos llegó a México en diciembre de 1955. A su regreso a Praga, la delegación rindió un informe poco halagador sobre la CTAL y Lombardo, en parte gracias a que uno de los informantes de los checoslovacos fue el comunista brasileño Lourival Villar, a la sazón uno de los secretarios de la CTAL, ansioso de transferir la dirección del movimiento obrero de la CTAL a un organismo en manos de los partidos comunistas. Lombardo era "un real individualista", quien se dedicaba a imprimir circulares, aparecía poco en las oficinas del secretariado y no aseguraba el trabajo colectivo. El informante redujo el trabajo de la CTAL a una frivolidad y se quejó de que Lombardo invitara a las delegaciones de Checoslovaquia, Polonia y Rumania a excursiones cuando la organización no tenía dinero para ese tipo de actividades. La delegación quedó gratamente impresionada por el sindicato electricista, independiente de la CTAL, por la cobertura del seguro social que proporcionaba a sus trabajadores y por su unificación con sindicatos pequeños. La delegación checoslovaca lamentó que el movimiento sindical progresista fuera dirigido por el "pequeñoburgués” Partido Popular y no por el Partido Comunista de México. ${ }^{16}$

La política de la coexistencia pacífica del gobierno de la URSS se presentaba ante el mundo como la distensión entre los dos bloques, pero en realidad ocultaba la tendencia a la recuperación de la conducción de los asuntos sindicales por los partidos comunistas. En octubre de 1956, Lombardo estaba en Sofía, Bulgaria, en la reunión del comité central de la CTAL con el secretariado de la Federación. El mundo comunista estaba todavía atónito por las revelaciones del secretario del partido, Nikita Jruschov, sobre el culto a la personalidad de Stalin y sobre los campos de trabajo forzado a los que fueron recluidos los perseguidos del régimen stalinista. Ante el peligro de la dispersión del mundo socialista, de la que las protestas populares en Polonia y Hungría eran las más fehacientes manifestaciones, la Federación, como correa de transmisión de la política soviética, incluyó a la CTAL y a Lombardo en la nueva alineación de las fuerzas políticas que poco tenían que ver con la situación real de Latinoamérica.

La detracción de la CTAL y de Lombardo Toledano reflejaba la impotencia de la Federación en un momento crítico del campo socialista. Saillant habló de la confusión de orientación en la dirección de la CTAL, de la sobreestimación del imperialismo y la reacción en Latinoamérica, y la subestimación de las fuerzas potenciales de lucha, la preferencia del partidismo sobre el sindicalismo y de la ideología sobre la organización. Ante los hechos, los comunistas latinoamericanos aprovecharon la situación crítica para presentarse como la alternativa para conducir el movimiento sindical, ya no desde México sino desde el sur del continente. ${ }^{17}$

Cuando Lombardo tomó la palabra, defendió a la CTAL, que había ayudado a crear centrales sindicales que la Federación Americana del Trabajo y Estados Unidos debilitaron al entablar pactos militares y convenios comerciales con los gobiernos latinoamericanos que asumieron el control de los sindicatos. Lombardo, quien nunca claudicaba en situaciones

FHLT, leg. 1013, Saillant a Hammerskjold, Leguy, Francia, 17 de febrero de 1956; FHLT, leg. 1017, Vicente Lombardo Toledano a Saillant, confidencial, ciudad de México, 20 de abril de 1956. En abril, la FSM se mudó a Praga.

16 "La situación de la CTAL y de su central sindical en México. Informe de la delegación checoslovaca en México, diciembre de 1955", Archivo del Departamento Internacional de la Central de los Sindicatos Revolucionarios de Checoslovaquia. El archivo consiste en cajas ordenadas cronológicamente, sin identificación.

17 FHLT, leg. 1027, "Reunión conjunta del comité central de la CTAL y del secretariado de la FSM", Sofía, Bulgaria, 4-6 de octubre de 1956. 
adversas, llamó la atención sobre la importancia de Latinoamérica en la lucha mundial contra el imperialismo, pero no podía hacerlo solo:

En la medida en que el imperialismo yanqui es batido en Europa, en Asia y en África, en la medida en que no logra sus objetivos, aprieta más el tornillo de la opresión sobre los países de la América Latina que representa en la actualidad su principal mercado, tanto para su comercio internacional cuanto para las fuentes de sus utilidades. ${ }^{18}$

Pero Lombardo Toledano estaba solo frente a la política de Estado de la Unión Soviética asumida por los partidos y dirigentes comunistas, incluyendo al cubano Lázaro Peña, con el que había fundado la CTAL. ${ }^{19}$ La siguiente reunión de la FSM tuvo lugar en Praga, en enero de 1957. Lombardo se enfrentó a una nueva embestida. Por las dificultades para entablar relaciones con los trabajadores en los países del continente,

nuestros camaradas — aliados de la FSM - deben penetrar en los órganos dirigentes de las organizaciones legales y gubernamentales, miembros de la ORIT [Organización Regional Interamericana de Trabajo] [...] y en las organizaciones autónomas y desarrollar en ellas actividad a favor de la línea de los trabajadores de la CTAL y la FSM. ${ }^{20}$

Si bien la dirección de la FSM calificó el trabajo de la CTAL contra el imperialismo como positiva, "los partidos comunistas son los luchadores más consecuentes para realizar esta tarea y [...] es necesario que estén a la cabeza de esta lucha de las amplias masas del pueblo trabajador". ${ }^{21}$ Además, en México, la CTAL tenía una influencia mínima, aunque sus órganos de propaganda eran de buen nivel. La Federación aplaudió su postura sobre la intervención militar en Hungría, en octubre de 1956, como ayuda fraternal de los Estados populares contra la actividad contrarrevolucionaria pagada por los círculos imperialistas. En suma, el trabajo de la CTAL desempeñaba un papel importante, pero carecía “de contacto vivo con las masas sindicalizadas". Como la dirección de la CTAL no tenía la capacidad de conectarse con el Sur, desde México, la FSM estableció una oficina de ayuda en Chile. ${ }^{22}$ De allí a decidir la desaparición de la CTAL había sólo un paso, que se dio en la siguiente reunión.

En Bucarest, Rumania, en diciembre de 1959, el buró ejecutivo de la Federación se reunió de nuevo con el comité central de la CTAL: "¿Ha llegado el momento de liquidar a la CTAL?". "No", argumentó un documento, escrito probablemente por Lombardo, pues su liquidación dejaría el camino libre a la ORIT y al imperialismo. ${ }^{23}$ Pero esta posición perdió ante la embestida de los delegados de Sudamérica que acudieron a Bucarest a defender al movimiento obrero en ascenso, aunque tuvieron que torcer los hechos. La CTAL exageraba las dificultades resultantes de la represión, existían posibilidades de llegar a acuerdos con la ORIT. La CTAL se ocupaba más de cuestiones políticas que de problemas sindicales y su secretariado no hacía suficiente esfuerzo para ligarse con el movimiento obrero. En esa reunión hablaron miembros de varios países. El venezolano Eloy Torres apuntó que los dirigentes sindicales pertenecían a los partidos políticos, lo que dividía el movimiento y sería la causa del derrocamiento del gobierno de

\section{Ibidem}

19 Ibidem.

20 Archivo del Departamento Internacional de la Central de los Sindicatos Revolucionarios de Checoslovaquia, "Reunión del consejo ejecutivo de FSM", Praga, Checoslovaquia, enero de 1957; "Informe político sobre la CTAL", Bedrich Pistora, embajador de Checoslovaquia, ciudad de México, 9 de julio de 1957.

21 Ibidem.

22 Ibidem

23 FHLT, leg. 1104, Secretariado del comité central de la CTAL, "La CTAL y los problemas de organización y de lucha del movimiento sindical en América Latina”, ciudad de México, octubre de 1959. 
Rómulo Gallegos en 1948. La dictadura feroz que lo reemplazó, la lucha por la democracia y el derrocamiento de la dictadura unieron a los sindicatos en la Confederación de Trabajadores de Venezuela, independiente de las centrales internacionales, aunque la ORIT ayudó a los dirigentes en el exilio. "La CTAL es una organización que tiene grandes méritos, pero que ha cumplido ya su misión histórica y debe abrir cauce a nuevas formas de organización en América Latina”, en lugar de ser fortalecida. Oscar García, de Argentina, dijo: "el secretariado de la CTAL se mantiene en el pasado, rumiando sus glorias". Enrique Pastorino, de Uruguay, ensalzó la Revolución cubana como el movimiento que había abierto "el camino de la lucha de los pueblos de América Latina”. El cubano Lázaro Peña enfatizó que había que luchar para que las organizaciones nacionales se desafiliaran de la ORIT, que tenía copado el movimiento sindical de la isla. Roberto Lara, de Chile, quería que se dejara morir a la CTAL y se creara una nueva central democrática. Gonzalo Sierra Cantillo, de Costa Rica, señaló que siempre había recibido asistencia y solidaridad de la CTAL, pero que había llegado el momento de unificación de la central de trabajadores con las organizaciones de todas las tendencias que veían en la CTAL una central sectaria. Víctor Manuel Zúñiga, de Ecuador, replicó a la crítica de la CTAL: "se recordará siempre que fue la voz de Vicente Lombardo Toledano y de la CTAL la que hizo la mejor defensa de nuestro derecho”. El chileno Ildefonso Alemán defendió a la CTAL contra el informe rendido por Saillant sobre su debilidad frente a la ORIT. El dirigente soviético Viktor Grishin y el checo František Zupka añadieron su voz sobre la perentoriedad de la entrada de los comunistas en los sindicatos independientes para, sin decirlo, controlarlos. Cuando Saillant retomó la palabra, tocó el problema que otros compartían: "La CTAL ha perdido la noción de que el movimiento sindical se dirige por la base" y no desde la cima. Hacía falta crear una organización que estuviera más cerca de las masas y las masas estaban en las organizaciones autónomas. Se propuso a las centrales de Chile, Venezuela y Cuba que tomaran la iniciativa para organizarla y al mismo tiempo desafiliar a las organizaciones que estaban en la ORIT. Había que disolver a la CTAL pero con el argumento de que era por el bien de la unidad y no por sus debilidades orgánicas. ${ }^{24}$

Lo que quedaba de autoridad de la CTAL y de Lombardo Toledano como representantes del movimiento obrero latinoamericano fue disuelto en Bucarest, donde maduró "la idea de liquidar prácticamente a la CTAL, para que las centrales sindicales independientes tomaran a su cargo la tarea de convocar a una conferencia por la unidad de acción, considerando que la CTAL podía ser un estorbo político para que esa conferencia se realizara con éxito". ${ }^{25}$ Ese hecho, escribió Lombardo con un dejo de amargura,

nos coloca también en la condición de un organismo que no tiene en el propio seno interior de México, públicamente, la posibilidad de ayudar, porque la ORIT y los diversos órganos de las Embajadas norteamericanas en los países de la América Latina se han encargado de hacer una campaña sistemática, diciendo que la liquidación de la CTAL es la mejor prueba de que la ORIT tiene razón y de que es la única internacional que existe. ${ }^{26}$

En diciembre de 1960, la Federación entregó a la CTAL un subsidio de 8421 dólares para 1961, y al año siguiente, de 7798.71 dólares, que fue el último y con el que se pagaron la indemnización y el aguinaldo del personal que trabajaba en las oficinas de

\footnotetext{
24 FHLT, leg. 1107, "Reunión conjunta del buró ejecutivo de la FSM y del cc de la CTAL", Bucarest, 10-12 y 13-16 de diciembre de 1959; FHLT, leg. 1111, Luigi Grassi a Vicente Lombardo Toledano, Praga, Checoslovaquia, 18 de enero de 1960.

25 Ibidem

26 FHLT, leg. 1123, Vicente Lombardo Toledano a Saillant, ciudad de México, 10 de noviembre de 1960.
} 
la CTAL, aunque no alcanzó para pagar la deuda de 7290 dólares con la aerolínea belga SABENA. Lombardo, al parecer solo, no veía la liquidación de la CTAL como una derrota, sino como una victoria, después de 25 años de vida, pues en enero de 1964 estaba por crearse una nueva organización sindical latinoamericana, lo que significaba que existía "un aguerrido destacamento del proletariado mundial". ${ }^{27}$

Los organizadores de la nueva central latinoamericana convocaron a Río de Janeiro, Brasil, para fundar una organización sindical en enero de 1964. Para la ocasión, Lombardo redactó el documento que anunciaba la disolución de la CTAL como la misión histórica cumplida. No asistió a la reunión, pues empezaba el proceso electoral en México y quería postularse para diputado por el Partido Popular Socialista y apoyar la candidatura de Gustavo Díaz Ordaz para la presidencia.

"La CTAL cumplió su misión histórica" fue su adiós a la Federación Sindical Mundial, y a Saillant, "por las batallas que libramos juntos por cerca de veinte años consecutivos". Lombardo Toledano quería salir airoso de esta debacle:

Al cumplir dentro de unos meses setenta años de edad y cerca de cincuenta años de combate diario por los derechos e intereses de la clase obrera y por el socialismo, tengo más confianza que nunca en el porvenir y más decisión que en el pasado para continuar en la más grande batalla de la historia de la humanidad a la que me incorporé desde que era estudiante de la Universidad Nacional de México. ${ }^{28}$

Nunca corto de grandilocuencia, Lombardo se despidió: "Quedo aquí, en mi patria, como un soldado de fila del proletariado". ${ }^{29}$ Combatiente siempre, es probable que Lombardo escribiera el editorial o artículo sin firma, titulado "El congreso sindical de Río de Janeiro que se reunirá durante los días del 24 al 28 de enero de 1964", en el que se auguraba: "no hay condiciones para crear una nueva organización sindical latinoamericana". Los que la convocaron eran un conglomerado de organizaciones y personalidades que no tenían una plataforma común. Entre ellos estaba Juan Lechín, vicepresidente de Bolivia "y anticomunista furibundo, pero que es el más importante de todos, porque agrupa a los mineros del país". Había organizaciones afiliadas a la ORIT y la CTAL, escribió después de haber propuesto esta mezcolanza ideológica en alguna ocasión, creyendo entonces que la CTAL pudiera lograr ascendencia sobre el resto. El autor del artículo, conocedor íntimo de la historia de la CTAL y la FSM, adjudicó a la FSM el haber privado a la CTAL de su apoyo político, lo que significaba haber privado a la FSM del apoyo obrero en Latinoamérica. Nadie sino Lombardo sabía que la "idea de liquidar a la CTAL y de crear un nuevo organismo sindical latinoamericano había surgido de los partidos comunistas de la América del Sur”, el argentino, desde 1950, y al que se unieron otros, como el mexicano, "que estuvo haciendo una gran campaña de mentiras con el fin de desplazar a Lombardo Toledano del movimiento sindical internacional". ${ }^{30}$ La CTAL desapareció, pero la nueva organización no tenía posibilidades de nacer y la ORIT “está íntegra para seguir combatiendo a los sindicatos de tendencias progresistas". Para echar más sal a la herida de Lombardo, un

27 FHLT, leg. 1124, Guiseppe Casadei a la CTAL, Praga, Checoslovaquia, 28 de diciembre de 1960; FHLT, leg. 1169, Saillant a Vicente Lombardo Toledano, Praga, Checoslovaquia, 16 de septiembre de 1963; FHLT, leg. 1171, Saludos de Vicente Lombardo Toledano, presidente de la CTAL, al XIII Congreso de los Sindicatos Soviéticos, Moscú, URSS, 30 de octubre de 1963. FHLT, leg. 1176, Vicente Lombardo Toledano a Saillant, ciudad de México, 1 de enero de 1964.

29 FHLT, leg. 1178, SABENA a Vicente Lombardo Toledano, 30 de enero de 1964; FHLT, leg. 1176, Vicente Lombardo Toledano a Saillant, ciudad de México, 7 de enero de 1964.

30 FHLT, leg. 1176, "El congreso sindical de Río de Janeiro que se reunirá durante los días del 24 al 28 de enero de 1964", ciudad de México, 7 de enero de 1964. 


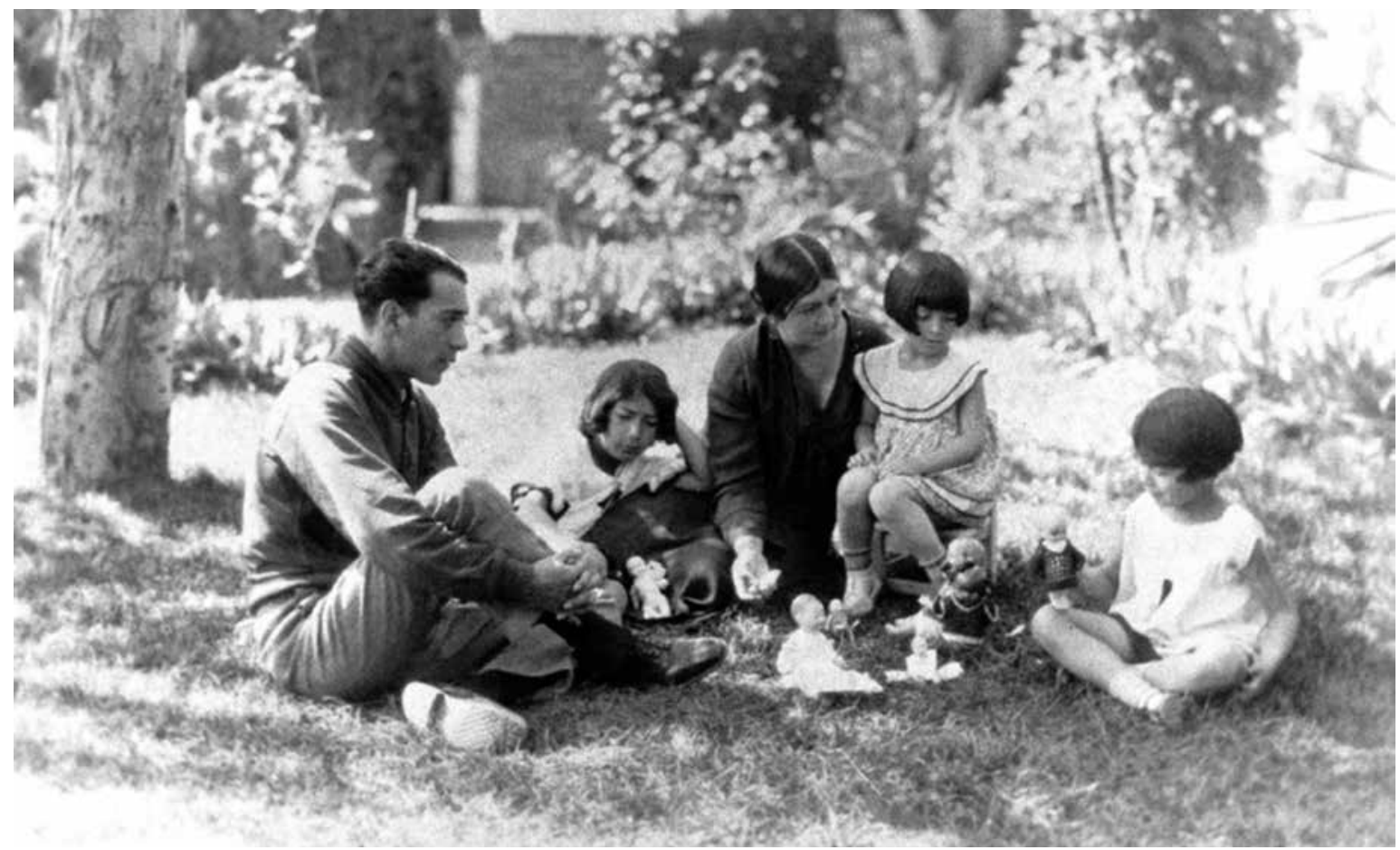

Centro de Estudios Filosóficos, Politicos y Sociales Vicente Lombardo Toledano • Vicente Lombardo Toledano, su esposa Rosa María Otero y Gama y sus hijas.

organizador chileno de la reunión de Río de Janeiro estuvo en México "sin visitar siquiera las oficinas de la CTAL, dando a entender que no [querían] tener más relaciones con Lombardo Toledano en el futuro". Lombardo estaba seguro de que detrás estaba el PCM, que se había convertido "en un verdadero grupo de provocación sin ninguna influencia real en el movimiento obrero ni entre las organizaciones democráticas importantes de México". Con su liquidación se estaba "destruyendo la obra que la Confederación de Trabajadores de América Latina [había logrado] hacer con muchos esfuerzos". ${ }^{31}$

Los autores de la convocatoria al congreso de unidad sindical para fundar la nueva organización no reconocieron a la CTAL como la precursora de la nueva entidad y la URSS dejó de ser el heraldo de la nueva patria y la emancipación americana. Por el contrario, invocaron a Cuba — “ "que se ha liberado integralmente" de la opresión, del imperialismo y de las castas feudales-, puesto que al igual que en la isla, sólo "profundos cambios estructurales" liquidarían la dominación imperialista y el colonialismo en Latinoamérica. ${ }^{32}$

\section{Reflexiones finales}

La ofensiva contra la CTAL tuvo un triple origen: la ORIT, que representaba a sindicatos no comunistas y anticomunistas en Latinoamérica, y la Federación

\footnotetext{
31 Ibidem.

32 FHLT, leg. 1178, "Convocatoria al congreso de unidad sindical de los trabajadores de América Latina", Río de Janeiro, 24-28 de enero de 1964, Montevideo, Uruguay, 28 de julio de 1963.
} 
Americana del Trabajo — que no se identificaba siempre con el gobierno de Estados Unidos cuando el Departamento de Estado instigaba o apoyaba golpes de Estado en el hemisferio-; los partidos comunistas que, mediados por la FSM, eran los vehículos de las políticas internacionales de la Unión Soviética, y la Revolución cubana con implicaciones continentales. Lombardo Toledano adjudicó la responsabilidad principal por la debacle de la CTAL a la Federación Americana del Trabajo y la ORIT. A los comunistas latinoamericanos, y en menor grado, a la Federación Sindical Mundial les atribuyó la otra parte de la responsabilidad y exoneró entonces y siempre a la Unión Soviética de cualquier transgresión legal, moral o política. A pesar de que Lombardo festejó el triunfo de la Revolución cubana, la consideró la continuidad de un proceso histórico, comenzado por la Revolución mexicana y no una ruptura con el pasado.

Lombardo Toledano creía en leyes históricas cuyo cumplimiento avanzaba así como retrocedía:

El panorama de la América Latina no puede ser peor. Fue disuelta la Confederación de Trabajadores de América Latina, a petición reiterada durante varios años de los dirigentes de los partidos comunistas de la América del Sur, con el objeto de que ellos pudieran manejar la organización sindical en nuestro Hemisferio, confundiendo una agrupación de masas con una internacional política. Cuando me di cuenta de que esos deseos estaban apoyados por la dirección de la Federación Sindical Mundial como usted recuerda facilité el camino para tal propósito. ${ }^{33}$

Al liquidar a la CTAL perdió sentido seguir siendo el vicepresidente de la FSM y asistir a sus reuniones que "no tendrían más objeto que el de despedirme de mis viejos compañeros y amigos, cosa que puedo hacer por medio de una carta". ${ }^{34}$

De ahí en adelante, Lombardo Toledano canceló su actividad sindical. Sin incorporar los nuevos argumentos de análisis que surgieron como consecuencia de las nuevas alineaciones políticas comandadas por el gobierno de la URSS, de las percepciones y motivaciones de la nueva izquierda radicalizada a raíz de la Revolución cubana, repetía que la CTAL había sido disuelta "a petición de los Partidos Comunistas de la América Latina, a iniciativa del Partido Comunista Mexicano, para tomar en sus manos el movimiento sindical": "Hace varios años advertí el error grave que iba a cometerse", y que la FSM aprobó. Mientras la ORIT perduraba: "nosotros no tenemos nada en este Continente. Fracasó la reunión de Brasil, y ahora después del último golpe de Estado y de las cosas que han ocurrido en otros países del sur, la situación no puede ser peor" ${ }^{35}$ En efecto, en Brasil no surgió la nueva organización latinoamericana que remplazaría a la CTAL y el presidente João Goulart fue derrocado por un golpe militar.

Lombardo Toledano no permitió que los sentimientos de derrota dominaran su ánimo. De manera sistemática negaba que lo subjetivo y las relaciones personales tuvieran importancia en la historia y rechazó a James Wilkie cuando tocó el tema: “yo no quiero ocuparme de cosas que no tienen valor para mí de ningún modo" (Wilkie y Monzón de Wilkie, 1969: 231). Lombardo consideraba accidental la subjetividad porque la historia se movía por leyes inexorables y él era su encarnación. Lombardo era un estratega que accedió a las entrevistas con James y Edna Wilkie para dar un testimonio "con destino académico", para que "la juventud de los Estados Unidos aproveche la experiencia de mi vida, en relación con una gran cosa: el movimiento revolucionario de México, con atisbos respecto de la humanidad" (Wilkie y Monzón de Wilkie, 1969: 312). Aquella parte de la historia que no edificaba, no tenía por qué ser revelada. D

\footnotetext{
33 FHLT, leg. 1198, Vicente Lombardo Toledano a Victor Grishin, 7 de noviembre de 1964.

34 Ibidem

35 FHLT, leg. 1193, Vicente Lombardo Toledano a Vittorio Vidali, ciudad de México, 18 de septiembre de 1964.
} 


\section{Bibliografía}

Calderón Vega, Luis, 1961, Los 7 sabios de México, s. e., México.

Carew, Anthony, 1984, "The Schism within the World Federation of Trade Unions: Government and Trade Diplomacy", en International Review of Social History, vol. XXIX, núm. 3, pp. 218-244.

Carr, Barry, 1994, "The Fate of the Vanguard under the Revolutionary State: Marxism's Contribution to the Construction of the Great Arch", en Gilbert Joseph y Daniel Nugent (eds.), Everyday Forms of State Formation. Revolution and the Negotiation of Rule in Modern Mexico, Duke University Press, Durham.

Herrera González, Patricio, 2013a, En favor de una patria de los trabajadores. La Confederación de Trabajadores de América Latina y su lucha por la emancipación del continente, 1938-1953, tesis de doctorado, El Colegio de Michoacán, Zamora.

—_, 2013b, “La Confederación de Trabajadores de América Latina. Una historia por (re)significar (1938-1963)”, en Secuencia, núm. 86, pp. 195-218.

, 2014, “Vicente Lombardo Toledano y el Congreso Obrero Latinoamericano (1935-1938)”, en Relaciones, vol. 35, núm. 138, pp. 109-150.

Krauze, Enrique, 1976, Caudillos culturales de la Revolución Mexicana, Siglo XXI Editores, México.

Lombardo Toledano, Vicente, 1964, La Confederación de Trabajadores de América Latina ha concluido su misión histórica, Popular, México.

—_, 2004, Obra histórico-cronológica, t. V, vol. 15-16: 1953, Centro de Estudios Filosóficos, Políticos y Sociales "Vicente Lombardo Toledano", México.

Rodríguez Castañeda, Rafael, 1995, “Prefacio”, en James Wilkie y Edna Monzón de Wilkie, Frente a la Revolución Mexicana: 17 protagonistas de la etapa constructiva, Universidad Autónoma Metropolitana, México.

Schwartz, Morton, 1963, Soviet Policy and the World Federation of Trade Unions, 1945-1949, tesis de doctorado, Universidad de Columbia, Nueva York.

Sturmthal, Adolf, 1948, "The Crisis of the WFTu”, en Industrial and Labor Relations Review, vol. 1, núm. 4, pp. 12-37.

Wilkie, James W. y Edna Monzón de Wilkie, 1969, México visto en el siglo xx. Entrevistas de historia oral, Instituto Mexicano de Investigaciones Económicas, México.

—_, 2004, Frente a la Revolución Mexicana. 17 protagonistas de la etapa constructiva. Entrevistas de historia oral, 4 vols., Universidad Nacional Autónoma de México, México.

Zolov, Eric, 2013, "Expanding our Conceptual Horizons: The Shift from an Old to a New Left in Latin America”, en Carlos Aguirre (ed.), Militantes, intelectuales y revolucionarios. Ensayos sobre marxismo e izquierda en América Latina, A Contracorriente, Raleigh.

\section{Archivos}

Archivo del Departamento Internacional de la Central de los Sindicatos Revolucionarios de Checoslovaquia, Praga, República Checa.

Fondo Histórico Lombardo Toledano (FHLT), Distrito Federal, México.

National Archives, Foreign Office, Kew Gardens, Reino Unido.

National Archives and Record Administration, Central Intelligence Agency Confidential Security Information, Washington, D. C., Estados Unidos.

The George Meany Memorial Archives, Silver Spring, Maryland, Estados Unidos. 